\title{
Inappropriate eating behavior: a longitudinal study with female adolescents
}

\author{
Comportamento alimentar inadequado: uma investigação longitudinal com adolescentes do sexo feminino
}

Comportamiento alimentar inadecuado: una investigación longitudinal con adolescentes del sexo femenino

Leonardo de Sousa Fortes ${ }^{1}$, Sebastião de Sousa Almeida ${ }^{2}$, Flávia Marcele Cipriani ${ }^{3}$ Maria Elisa C. Ferreira ${ }^{1}$

\section{ABSTRACT}

Objective: To evaluate the inappropriate eating behaviors (IEB) of female adolescents over a one-year period.

Methods: 290 adolescents aged between 11 and 14 years old participated in the three research stages (T1: first four months, T2: second four months and T3: third four months). The Eating Attitudes Test (EAT-26) was applied to assess the IEB. Weight and height were measured to calculate body mass index (BMI) in the three study periods. Analysis of variance for repeated measures was used to analyze the data, adjusted for the scores of the Body Shape Questionnaire and the Brazil Economic Classification Criteria.

Results: Girls at T1 showed a higher frequency of IEB compared to T2 $(p=0.001)$ and T3 $(p=0.001)$. The findings also indicated higher values for $\mathrm{BMI}$ in $\mathrm{T} 3$ in relation to $\mathrm{T} 1$ $(p=0.04)$. The other comparisons did not show statistically significant differences.

Conclusions: IEB scores of female adolescents declined over one year.

Key-words: feeding behavior; adolescent; eating disorders.

\section{RESUMO}

Objetivo: Avaliar os comportamentos alimentares inadequados (CAI) de adolescentes do sexo feminino ao longo de um ano.
Métodos: Participaram das três etapas (T1: primeiro quadrimestre, T2: segundo quadrimestre e T3: terceiro quadrimestre) da pesquisa 290 jovens de 11 a 14 anos. Utilizou-se o Eating Attitudes Test (EAT-26) para avaliar os CAI. Peso e estatura foram aferidos para calcular o índice de massa corpórea (IMC) nas três etapas. Os escores do Body Shape Questionnaire e dos Critérios de Classificação Econômica Brasil foram controlados nas análises estatísticas. Utilizou-se a ANOVA de medidas repetidas para analisar os dados.

Resultados: Evidenciou-se que, em T1, as meninas demonstraram maior frequência de CAI quando comparadas a T2 $(p=0,001)$ e T3 $(p=0,001)$. Além disso, os achados indicaram maior valor para o IMC em T3 em relação a T1 $(p=0,04)$. As demais comparações em razão da etapa da investigação não apontaram diferenças estatisticamente significativas.

Conclusões: Concluiu-se que os escores de CAI de adolescentes do sexo feminino diminuiram no decorrer de um ano.

Palavras-chave: comportamento alimentar; adolescente; transtornos da alimentação.

\section{RESUMEN}

Objetivo: Evaluar los comportamientos alimentares inadecuados (CAI) de adolescentes del sexo femenino a lo largo de un año.

Métodos: Participaron de las tres etapas (T1: primer cuadrimestre; T2: segundo cuadrimestre y $\mathrm{T} 3$ : tercero cuadrimestre)
Instituição: Faculdade de Educação Física e Desportos da Universidade Federal de Juiz de Fora (UFJF), Juiz de Fora, MG, Brasil

'UFJF, Juiz de Fora, MG, Brasil

2Universidade de São Paulo (USP), Ribeirão Preto, SP, Brasil

${ }^{3}$ Pontifícia Universidade Católica de Minas Gerais (PUC-MG), Juiz de Fora, MG, Brasil

\author{
Endereço para correspondência: \\ Leonardo de Sousa Fortes \\ Rua Hameleto Fellet, 20/201 - Vale do Ipê \\ CEP 36036-130 - Juiz de Fora/MG \\ E-mail: leodesousafortes@hotmail.com \\ Conflito de interesse: nada a declarar \\ Recebido em: 1/7/2013 \\ Aprovado em: 28/8/2013
}


de la investigación 290 jóvenes de 11 a 14 años. Se utilizó el Eating Attitudes Test (EAT-26) para evaluar los CAI. Peso y estatura fueron verificados para calcular el índice de masa corporal (IMC) en las tres etapas. Los escores del Body Shape Questionnaire y de los Criterios de Clasificación Económica Brasil fueron controlados en los análisis estadísticos. Se utilizó ANOVA de medidas repetidas para analizar los datos.

Resultados: Se evidenció que, en T1, las muchachas demostraron mayor frecuencia de CAI cuando comparadas a $\mathrm{T} 2$ $(p=0,001)$ y T3 $(p=0,001)$. Además, los hallazgos indicaron mayor valor para el IMC en T3 respecto a T1 $(p=0,04)$. Las demás comparaciones respecto a la etapa de la investigación no mostraron diferencias estadísticamente significativas.

Conclusiones: Se concluyó que los escores de CAI de adolescentes del sexo femenino se redujeron en el periodo de un año.

Palabras clave: comportamiento alimentar; adolescente; trastornos de la alimentación.

\section{Introduction}

Inappropriate eating behaviors (IAB) are considered deleterious health behaviors ${ }^{(1,2)}$. Examples of IAB: self-induced vomiting, food restriction for long periods, use of laxatives, diuretics, anabolic-androgenic steroids, among others ${ }^{(3)}$. According to Rodgers, Chabrol, and Paxton ${ }^{(4)}$, subjects diagnosed with eating disorders (EDs), such as anorexia nervosa and bulimia nervosa, use IEBs to reduce or maintain body weight. Evidence indicates low prevalence of IEB in the Brazilian population ${ }^{(5,6)}$. However, the prevalence of these behaviors can be pronounced in the teenage population ${ }^{(7,8)}$. More specifically, findings show that women are more likely to adopt IEB as a regular habit ${ }^{(9,10)}$.

Adolescence is the period comprised between 10 and 19 years of age, according to the World Health Organization $^{(11)}$. At this stage, young girls undergo numerous physical, sociological, and psychological changes ${ }^{(12,13)}$. For instance, some maturational events, such as menarche and peak height velocity, are considered remarkable characteristics of adolescence ${ }^{(14)}$; moreover, evidence suggests increased body fat in females throughout adolescence ${ }^{(14,15)}$. Nevertheless, it is noteworthy that the morphological pattern socially promoted in Western culture is inversely proportional to what young girls demonstrate on this phase of life, because, if, on the one hand, the maturational process impacts the increase in body fat, on the other, the media conveys the message that the skinny body is the socially accepted standard ${ }^{(16)}$. In this sense, it is likely that some adolescents feel pressured and adopt IEBs as an alternative measure to reduce body fat.

The scientific literature has shown some factors associated with IEB, such as: body dissatisfaction, socioeconomic status, and body mass index (BMI), among others ${ }^{(8-10)}$. However, a large portion of these studies used a cross-sectional design as an investigative method. According to some authors, crosssectional studies, although important, do not allow causal interferences ${ }^{(4)}$. This means that there is no way to assess the degree of intensity and the direction of the associations between the outcome of the study and the independent variables. It is noteworthy, still, that very few studies in the area of IEB used a longitudinal design ${ }^{(1,4,16)}$; however, none was conducted with young Brazilians. Furthermore, we emphasize that few investigations have been concerned with controlling external variables that could influence the IEBs somehow. Thus, it is suggested that body dissatisfaction, socioeconomic status, and BMI be controlled in studies that use IEB as a variable-criterion ${ }^{(15)}$. Given these arguments, the objective of this study was to evaluate the IEBs of female adolescents over a period of 1 year.

Therefore, some hypothesis were formulated based on previous studies $\left.{ }^{(1,4)}: 1\right)$ there is an increased prevalence of IEB indicating risk for EDs among adolescents in the course of a year; 2) the frequency of IEB increases over a year.

\section{Method}

The present investigation was a longitudinal, schoolbased study, conducted in 2012 in the municipality of Juiz de Fora, state of Minas Gerais, with female adolescents in the age range between 11-14 years.

According to information from the Department of Education of Juiz de Fora (www.pjf.mg.gov.br/se), the population of female adolescents in the age range of the study, enrolled in municipal schools in 2011, was of approximately 20,000 students. Thus, sample size calculation was performed with the following criteria, according to recommendations by Alves et a $l^{(17)}$ : prevalence of $20 \%$ for IEB according to findings by Scherer $e t a l^{(10)}$ and Martins $e t a l^{(9)}, 95 \%$ confidence, $5 \%$ sampling error, and 1.2 for design effect, totaling thus, 246 young girls composing a representative sample of the population in question.

The sample was stratified according to the proportional inclusion of schools in socio-geographic regions of the 
municipality of Juiz de Fora (north, south, and center) and the type of governmental involvement (public or private), and then, distributed in elementary schools. The selection occurred randomly through simple drawing, in two stages. First, the draw of schools was held in each region and then the draw of teens in these units. The schools were selected with the help provided by the statistics unit of the Department of Education of the state of Minas Gerais. The final sample of the survey was distributed in six different collection points (schools) and consisted of adolescents attending the school on the days of collection.

The study included only the girls who handed over the free informed consent signed by the parents or guardians and who were regularly enrolled in elementary school in the municipality of Juiz de Fora in 2012.

There were 368 female participants, and 78 were excluded for not completing the questionnaire in full or not participating in the anthropometric assessments in the three stages of the research or, for being absent in some stage of the research. In stage 1 (T1: first four months), 368 girls were assessed. In stage 2 (T2: second four-month period), there was a sample loss of 42 adolescents. Then, in stage 3 (T3: third quadrimester), 36 students were excluded.

The instruments used for the study were the Eating Attitudes Test (EAT-26), the Body Shape Questionnaire (BSQ), besides the Brazilian Economic Classification Criterion (BECC), and anthropometric measurements.

We used the EAT-26 to assess IEBs. It is a self-report tool with 26 items, with responses in Likert-like scale (0: never, almost never, or rarely, 1: sometimes, 2: many times, 3: always ), and the question number 25 presents reversed score. These questions are divided into three subscales, namely: 1) diet - related to the pathological refusal of foods with high calories and concern with physical appearance; 2) bulimia and preoccupation with food - refers to episodes of binge eating followed by purging behaviors for loss/control weight; and 3) oral self-control - reflects self-control in relation to food and evaluates environmental and social forces stimulating food intake. Scores equal to or greater than 21 indicate risk behavior for EDs. We used the version of the EAT-26 proposed for females ${ }^{(18)}$. The authors performed the translation and back-translation of the instrument and obtained a Cronbach's alpha of 0.82 , indicating its use for studies with similar samples. In order to prove the suitability of the instrument to this sample, we calculated the internal consistency of the EAT-26, obtaining a Cronbach's alpha value ranging from 0.83 to 0.89 in all stages of the research.
The BSQ is a self-report instrument consisting of 34 questions in the form of Likert scale of points, ranging from 1 - never, to 6 -always, seeking to evaluate the frequency of concern/ dissatisfaction that the young has with weight and physical appearance, i.e., body dissatisfaction. The higher the score, the greater the depreciation the assessed has with his or her body appearance. This questionnaire has been validated for the Brazilian adolescent population ${ }^{(19)}$, showing good psychometric properties. For this sample, the internal consistency was calculated by Cronbach's alpha, obtaining a satisfactory value from 0.86 to 0.92 in all stages of the research. Considering that body dissatisfaction can influence $\operatorname{IEB}^{(4,10)}$, we chose to control the scores of the BSQ in the data analysis.

Socioeconomic status was obtained by applying the BECC, developed by the Brazilian Association of Research Companies ${ }^{(20)}$. The BECC emphasizes its function of estimating the purchasing power of people and urban families, abandoning the pretension of classifying the population in terms of "social classes". This instrument assesses the amount of comfort items (car, refrigerator, television, etc.) purchased, and identifies the level of education of the household head. The higher the score, the higher the socioeconomic level. Because some studies demonstrate the influence of socioeconomic status on $\operatorname{IEB}^{(4,16)}$ and the present investigation includes participants with possible differences in socioeconomic status (public schools versus private schools), it was decided to enter the scores of the CCEB as a covariate in the statistical analyzes.

Anthropometric data were collected by the same evaluator, who was trained for this measurement. Body mass was measured with a portable digital scale (Tanita ${ }^{\circledR}$ ) with $100 \mathrm{~g}$ precision and maximum capacity of $200 \mathrm{~kg}$. We used a portable stadiometer with precision of $0.1 \mathrm{~cm}$ and maximum height of $2.20 \mathrm{~m}$ (Welmy ${ }^{\circledR}$ ) to measure the height of adolescents, according to the methodology proposed by the International Society for Advancement for Kineanthropometry ${ }^{(21)}$. We obtained BMI by calculating: BMI = body mass index $(\mathrm{kg}) /$ height $\left(\mathrm{m}^{2}\right)$. By criterion of reliability, we decided to calculate the curve of BMI for age, following the procedures previously performed in another study $^{(22)}$, with the purpose to check whether the results would be the same. Thus, the results indicated no statistical differences in any of the stages of the investigation.

The directors of ten schools (five public and five private) were invited to participate in the study, being informed about the study objectives and procedures. However, only 
six (three from public and three from private institutions) agreed to participate, and, once we had the authorizations, meetings were held with each class in order to explain the objectives and procedures for inclusion of adolescents in the study. The term of free and informed consent was handed to the adolescents, and we asked them to return them signed by parents or guardians in the following week, in case of assent of their voluntary participation.

The research was divided into two moments. In the first one, the students completed the instruments (EAT-26, BSQ, and CCEB), and a qualitative questionnaire to identify demographic data (age). This stage was performed in group, by a single researcher, who standardized verbal explanations in an attempt to avoid intra-rater interference.

After the questionnaires were completed, the students were led into another room, dressed in the uniform for Physical Education classes and barefoot. In this second stage, anthropometric data were measured individually and only one student was allowed in the room at a time. These procedures were repeated three times throughout the year 2012, with a four-month interval between assessments (February - T1, June - T2, and October - T3).

Table 1 - Descriptive variables of the sociodemographic and anthropometric variables according to time (T1, T2 and T3). Juiz de Fora, 2012

\begin{tabular}{lccc}
\hline Variable & T1 & T2 & T3 \\
\hline Age (years) & $12.4 \pm 1.5$ & $12.5 \pm 1.6$ & $12.7 \pm 1.6$ \\
Weight $(\mathrm{kg})$ & $48.8 \pm 11.6$ & $47.9 \pm 11.5$ & $48.9 \pm 12.2$ \\
Height $(\mathrm{m})$ & $1.55 \pm 0.86$ & $1.55 \pm 0.88$ & $1.55 \pm 0.70$ \\
BMI $\left(\mathrm{kg} / \mathrm{m}^{2}\right)$ & $19.47 \pm 3.76$ & $20.03 \pm 3.67$ & $20.15 \pm 4.15^{*}$ \\
BSQ & $79.96 \pm 35.29$ & $68.95 \pm 35.29$ & $64.83 \pm 32.97$ \\
BECC & $18.93 \pm 4.89$ & $17.44 \pm 4.22$ & $18.08 \pm 4.15$ \\
\hline
\end{tabular}

${ }^{*} p<0.05$ in relation to $\mathrm{T} 1$; Values presented as mean \pm standard deviation T1: Stage 1; T2: Stage 2; T3: Stage 3; BMI: body mass index; BSQ: Body Shape Questionnaire; BECC: Brazilian Economic Classification Criterion

Table 2 - Minimum and maximum anthropometric variables in relation to time. Juiz de Fora, 2012

\begin{tabular}{lcccccc}
\hline \multirow{2}{*}{ Variable } & \multicolumn{2}{c}{ T1 } & \multicolumn{2}{c}{ T2 } & \multicolumn{2}{c}{ T3 } \\
\cline { 2 - 7 } & Min & Max & Min & Max & Mín & Max \\
\hline Weight $(\mathrm{kg})$ & 21.7 & 84.5 & 23.2 & 89.0 & 25.0 & 93.3 \\
Height $(\mathrm{m})$ & 1.24 & 1.76 & 1.27 & 1.80 & 1.30 & 1.72 \\
BMI $\left(\mathrm{kg} / \mathrm{m}^{2}\right)$ & 12.8 & 31.8 & 13.2 & 32.5 & 13.1 & 34.1 \\
\hline
\end{tabular}

T1: Stage 1; T2: Stage 2; T3: Stage 3; BMI: body mass index; Min: minimum; Max: maximum
This study was approved by the Research Ethics Committee of Universidade Federal de Juiz de Fora (protocol 2282.022.2011), according to the law n. 196/96 of the National Health Council.

In the statistical analysis, we used the KolmogorovSmirnov test to assess the distribution of the data. Due to the non-parametric violation, we used measures of central tendency (mean), dispersion (minimum, maximum, standard deviation, and error), and frequency to describe the research variables. We used de Student's $t$ test to compare the scores of the EAT-26 in relation to governmental involvement (private and public) in the three stages of the research. We used Pearson's correlation to associate the EAT-26 scores with all the independent variables (age, weight, height, BMI, $\mathrm{BSQ}$, and CCEB) in the three stages of investigation. We used Person's chi-square for a variable in order to compare the prevalence of IEB in relation to time (T1, T2, and T3). We conducted analysis of variance for repeated measures (ANOVA) to compare age, weight, height, and BMI in relation to time (T1, T2 and T3). The same analysis was applied to compare the scores of the EAT-26 for each of the stages of the research (T1, T2 and T3), using age, BSQ, BECC, and BMI as covariates. We used the Bonferroni post hoc test to identify statistical differences. All data were processed in the Statistical Package for the Social Sciences (SPSS) 17.0, and statistical significance was established at $5 \%$.

\section{Results}

There were 290 female adolescent participants in total, whose means for age, weight, height, BMI, BSQ, and BECC are described in Table 1.

In T1, there were 368 girls stratified according to age as follows: 95 with 11 years, 92 with 12 years, 89 with 13 years, and 92 with 14 years. In T2, there was a sample loss of 42 girls, and the remaining 326 were distributed according to age as follows: 86 with 11 years, 83 with 12 years, 72 with 13 years, and 85 with 14 years. Finally, it T3, there was a new loss of 36 students. Thus, the distribution of the 290 adolescents according to age was the following: 80 with 11 years, 72 with 12 years, 57 with 13 years, and 81 with 14 years.

Regarding minimum and maximum values of the anthropometric variables in relation to time, the results are presented in Table 2. Changes were demonstrated in the dispersions of these variables in the three moments ( $\mathrm{T} 1$, $\mathrm{T} 2$, and $\mathrm{T} 3$ ). 
Table 3 - Associations between the Eating Attitudes Test scores and the independent variables in the three stages of the research. Juiz de Fora, 2012

\begin{tabular}{|c|c|c|c|c|c|c|c|}
\hline & EAT-26 & Age & Weight & Height & BMI & BSQ & CCEB \\
\hline \multicolumn{8}{|l|}{ T1 } \\
\hline EAT-26 & - & 0.02 & 0.13 & -0.15 & $0.21^{*}$ & $0.62^{* *}$ & $0.25^{*}$ \\
\hline Age & - & - & $0.38^{* *}$ & $0.45^{* *}$ & $0.29^{*}$ & 0.09 & 0.11 \\
\hline Weight & - & - & - & $0.58^{* *}$ & $0.94^{* *}$ & $0.78^{* *}$ & 0.04 \\
\hline Height & - & - & - & - & $0.28^{*}$ & 0.17 & 0.08 \\
\hline BMI & - & - & - & - & - & $0.69^{* *}$ & 0.16 \\
\hline$B S Q$ & - & - & - & - & - & - & 0.14 \\
\hline \multicolumn{8}{|l|}{ T2 } \\
\hline EAT-26 & - & -0.14 & 0.15 & -0.07 & $0.25^{*}$ & $0.58^{* *}$ & $0.23^{*}$ \\
\hline Age & - & - & 0.08 & 0.14 & 0.10 & 0.05 & 0.08 \\
\hline Weight & - & - & - & $0.64^{* *}$ & $0.89^{* *}$ & $0.71^{* *}$ & 0.06 \\
\hline Height & - & - & - & - & $0.23^{*}$ & 0.14 & 0.07 \\
\hline BMI & - & - & - & - & - & $0.64^{* *}$ & 0.05 \\
\hline $\mathrm{BSQ}$ & - & - & - & - & - & - & 0.09 \\
\hline \multicolumn{8}{|l|}{ T3 } \\
\hline EAT-26 & - & 0.03 & 0.08 & -0.06 & $0.13^{*}$ & $0.61^{* *}$ & $0.20^{*}$ \\
\hline Age & - & - & 0.18 & $0.33^{*}$ & 0.08 & 0.08 & 0.04 \\
\hline Weight & - & - & - & $0.58^{* *}$ & $0.94^{* *}$ & $0.75^{* *}$ & 0.03 \\
\hline Height & - & - & - & - & $0.28^{*}$ & 0.12 & 0.10 \\
\hline BMI & - & - & - & - & - & $0.60^{* *}$ & 0.06 \\
\hline $\mathrm{BSQ}$ & - & - & - & - & - & - & 0.12 \\
\hline
\end{tabular}

${ }^{*} p<0.05 ;{ }^{* *} p<0.01$. BMI: body mass index; BSQ: Body Shape Questionnaire; BECC: Brazilian Economic Classification Criterion; T1: Stage 1; T2: Stage 2; T3: Stage 3

Table 4 - Distribution of the prevalence of the Eating Attitudes Test ratings and description of test scores (mean and standard deviation) according to time. Juiz de Fora, 2012

\begin{tabular}{lccc}
\hline Variable & T1 & T2 & T3 \\
\hline \multicolumn{2}{l}{ Prevalence $(\%)$} & of classifications \\
EAT-26<21 & 75.9 & 90.4 & 94.8 \\
EAT-26 $\geq 21$ & $21.2^{*}$ & 9.6 & $5.2^{* *}$ \\
Mean (SD) of EAT-26 & & \\
EAT-26 & $15.88(1.06)^{*}$ & $11.88(1.26)$ & $11.75(1.36)^{* *}$ \\
\hline
\end{tabular}

${ }^{*} p<0.05$ in relation to $\mathrm{T} 2 ;{ }^{* *} p<0.05$ in relation to T1. T1: Stage 1; T2: Stage 2; T3: Stage 3

Regarding the comparisons of the EAT-26 scores in relation to governmental involvement, the findings indicated no statistically significant differences in $\mathrm{T} 1(F(1.367)=3.24$; $t=1.6 ; p=0.023) ; \mathrm{T} 2(F(1.325)=2.95 ; t=1.41 ; p=0.27)$ and $\mathrm{T} 3(F(1.289)=2.63 ; t=1.79 ; p=0.34)$.
The associations of the EAT-26 scores with the independent variables of the survey can be seen in Table 3. We highlight the significant associations found between the scores of the EAT-26 with BMI and the scores of BSQ and BECC in the three moments of the investigation.

The prevalences of the EAT-26 classifications according to the moment (T1, T2 and T3) are described in Table 4. There are differences in the classification "EAT $\geq 21$ " between $\mathrm{T} 1$ and $\mathrm{T} 2\left(\chi^{2}=13.41 ; p=0.01\right)$ and T1 and T3 $\left(\chi^{2}=17.33 ; p=0.01\right)$.

Regarding the comparison of the scores of the EAT-26 and BMI according to T1, T2 and T3, we identified important results (Table 4): 1) It was proved that, in T1, girls demonstrated higher frequency of IEB when compared to T2 $(p=0.001)$ and T3 $(p=0.001) ; 2)$ the findings indicated a greater value for $\mathrm{BMI}$ in $\mathrm{T} 3$ in relation to $\mathrm{T} 1(p=0.04)$. The other comparisons due to the stage of the investigation did not show statistically significant differences. It is noteworthy, however, that the ANOVA for repeated measures indicated that BMI, BSQ, and BECC were related to the EAT-26 scores. In contrast, age showed no collinearity with the IEBs. 


\section{Discussion}

The present study aimed to evaluate IEBs of female adolescents throughout a year. The findings, in general, showed a reduction in the frequency and prevalence of IEB in the course of a year. It should be noted that the choice of investigating adolescents in the age range of 11-14 years was due to the fact that the scientific literature mentions this phase as the most susceptible to the triggering of $\operatorname{EDs}^{(15,22,23)}$.

Regarding the prevalence of IEB, the findings of the present investigation point statistically significant differences in the period of a year. Contrary to what the scientific literature has shown ${ }^{(1,16)}$, there was a reduction in the prevalence of IEB from T1 to T2. Similarly, we found a lower prevalence of IEB in $\mathrm{T} 3$ compared to T1. These results indicate that girls showed reduced risk for EDs through the year 2012. Two possibilities can explain these findings: 1 ) the adolescents omitted the real answers on the EAT-26 in T2 and T3; or 2) the advancement of female adolescence can be considered a protective factor against the IEB. In other words, adolescents, after T1, for having acquired knowledge about what the EAT-26 seeks to evaluate, may have omitted their eating problems in stages $\mathrm{T} 2$ and $\mathrm{T} 3$. On the other hand, there is the possibility of younger girls having increased risks for IEB. In this sense, the progression of puberty could reduce the prevalence of female adolescents who adopt IEB as a daily habit. Evidence has pointed younger girls as being more prone to IEB ${ }^{(4,15)}$. It should be noted, however, that females during adolescence have a close relation with the increase in body fat, a morphological aspect that is depreciated in Western culture ${ }^{(13)}$. Therefore, young girls see IEBs as a method for rapid reduction of body fat.

Regarding the comparison of the EAT-26 scores in the stages of the research, the findings showed differences. Adolescents showed higher frequency of IEB in T1 when compared to $\mathrm{T} 2$ and $\mathrm{T} 3$. The results indicate that, when the girls were younger, they presented higher risks for EDs. Accordingly, 8 months were sufficient to reduce the frequencies of IEB. Some factors to explain these findings should be highlighted. For instance, some authors argue that younger adolescents often feel more pressure to reduce body weight ${ }^{(15)}$, which makes them more susceptible to the adoption of IEBs. It is noted, however, that the ANOVA for repeated measures showed no collinearity of the age with the EAT-26 scores, indicating that age factor did not explain the variance of the IEBs in this sample. Nevertheless, it has been shown that it is not chronological age that leaves young females more or less susceptible to IEBs, but the biological age ${ }^{(15)}$. These authors found that the younger girls are biologically more vulnerable to IEB. Considering that, in a year, it is possible that the biological age of these teens has advanced, then, the results of this research can be explained.

Although there have been no differences for age, weight, and height, the results showed an increase in mean BMI when $\mathrm{T} 1$ and $\mathrm{T} 33$ were compared. Other findings corroborate this trend ${ }^{(12,13)}$. The increase in BMI that may occur during adolescence is due to the influence of body weight increase which, in turn, is more related to the increase in body fat in girls ${ }^{(15)}$. Mirwald $e t$ a $l^{(14)}$ point out that body fat during puberty in girls is increased by factors such as menarche and hormonal preparation to reproduce the species.

As for comparisons of the EAT-26 scores in relation to administrative involvement (public or private), there was no difference in any of the three stages of the research. However, Dunker et $a^{(8)}$ point out that the IEB are more common in adolescents with high socioeconomic status. Therefore, we expected to identify higher EAT-26 scores in adolescents attending private schools. Perhaps the governmental involvement in which the adolescents are inserted is not an indicator of socioeconomic status. It is possible that low-income adolescents have scholarships in private institutions, and therefore, have exemption from enrollment and tuition. Likewise, it is possible that adolescents from high socioeconomic levels are enrolled in public schools, which explain the similarity between IEB among adolescents from private and public institutions in this investigation.

As for associations, the results showed the IEB relationship with body dissatisfaction, socioeconomic status, and BMI in the three stages of the research. It is noteworthy that the associations between IEBs and body dissatisfaction showed greater magnitude. Other findings corroborate these data $^{(1,4,9,10,16)}$. In fact, body dissatisfaction has a close relationship with IEB in female adolescents ${ }^{(1,9)}$, and an association with socioeconomic status was also demonstrated ${ }^{(8,24)}$, being more common in young people belonging to the higher strata of society $^{(8)}$. Finally, studies have shown that BMI also usually shows association with $\mathrm{IEB}^{(9,23)}$. Gondoli et $a l^{(1)}$ argue that high BMI values are associated with higher frequencies of IEB. Although the findings have indicated association of IEB with $\mathrm{BMI}$ in the three stages of the study, weight and height were not associated with IEB in female adolescents. Similarly, there was no association between IEB and age. According to Fortes and Ferreira ${ }^{(25)}$, the fact that young girls do not care about height, this anthropometric characteristic is little related to the IEB. These authors also point out that chronological age 
alone affects the IEB in males, which, somehow, explains the results of this research. However, due to the results of other studies $^{(9,16)}$, we expected to find association of IEBs with body weight, which in fact, did not happen.

The present study showed interesting and unpublished results, but it has limitations. One of them was the use of selfreported measures. Researchers point out that young people may not answer truthfully to the questionnaires ${ }^{(24,26)}$. However, Fortes and Ferreira ${ }^{(25)}$ and Schubert et $a l^{(27)}$ emphasize that, in studies with larger samples, self-administered instruments may be considered the gold standard for presenting easy application and low operational cost. Moreover, it is noteworthy that the sample loss during the 8 months of research can also be considered another limitation. It is emphasized, above all, that such losses were caused because of absences of students in T2 (37 adolescents) and T3 (25 adolescents), incomplete anthropometric data ( $\mathrm{T} 2=2$ and $\mathrm{T} 3=8$ young), or questionnaires

\section{References}

1. Gondoli DM, Corning AF, Salafia EH, Bucchianeri MM, Fitzsimmons EE. Heterosocial involvement, peer pressure for thinness, and body dissatisfaction among young adolescent girls. Body Image 2011;8:143-8.

2. Waller G, Sines J, Meyer C, Mounford V. Body checking in the eating disorders: association with narcissistic characteristics. Eat Behav 2008;9:163-9.

3. Gonçalves SF, Gomes AR. Exercising for weight and shape reasons vs. health control reasons: the impact on eating disturbance and psychological functioning. Eat Behav 2012;13:127-30.

4. Rodgers R, Chabrol H, Paxton SJ. An exploration of the tripartite influence model of body dissatisfaction and disordered eating among Australian and French college women. Body Image 2011;8:208-15.

5. Alvarenga MS, Scagliusi FB, Philippi ST. Eating disorders risk behavior in Brazilian female university students. Rev Psiquiatr Clin 2011;38:3-7.

6. Oliveira LL, Hutz CS. Eating disorders: the role of cultural aspects in the contemporary world. Psicol Estud 2010;15:575-82.

7. Alves TC, Santana ML, Silva RC, Pinto EJ, Assis AM. Factors associated with symptoms of eating disorders among students from public schools in Salvador, Bahia. J Bras Psiquiatr 2012;61:55-63.

8. Dunker KL, Fernandes CP, Carreira-Filho D. Socioeconomic influence on eating disorders risk behaviors in adolescents. J Bras Psiquiatr 2009;58:156-61.

9. Martins CR, Pelegrini A, Matheus SC, Petroski EL. Body image dissatisfaction and its relationship with nutritional status, body fat, and anorexia and bulimia symptoms in adolescents. Rev Psiquiatr RS 2010;32:19-23.

10. Scherer FC, Martins CR, Pelegrini A, Matheus SC, Petroski EL. Body image among adolescents: association with sexual maturation and symptoms of eating disorders. J Bras Psiquiatr 2010;59:198-202.

11. De Onis M, Onyango AW, Borghi E, Siyam A, Nishida C, Siekmann J et al. Development of a WHO growth reference for school-aged children and adolescents. Bull World Health Organ 2007;85:660-7.

12. Baxter-Jones AD, Eisenmann JC, Sherar LB. Controlling for maturation in Pediatric exercise science. PES 2005;17:18-30.

13. Siervogel RM, Demerath EW, Schubert C, Remsberg KE, Chumlea WC, Sun S et al. Puberty and body composition. Horm Res 2003;60 (Suppl 1):36-45.

14. Mirwald RL, Baxter-Jones AD, Bailey DA, Beunen GP. An assessment of maturity from anthropometric measurements. Med Sci Sports Exerc 2002;34:689-94.

15. Fortes LS, Almeida SS, Ferreira ME. Maturation process, body dissatisfaction and inappropriate eating behavior in young athletes. Rev Nutr 2012;25:575-86. delivered with incomplete answers in these stages of the research (T2 $=3$ and $\mathrm{T} 3=3$ school). It is also recognized that these facts may have biased the findings of this study. However, because of the considerably large final sample size (greater than needed for the representative population), it is believed that this loss of participants has reduced the information bias that could influence the results. Finally, it is estimated that this is the first study conducted in Brazil comparing IEBs over time in adolescent females.

The results showed that both the prevalence and the scores of IEBs in female adolescents declined in the course of a year. We recommend further investigations with longitudinal characteristics related to affective and behavioral variables among adolescents in both sexes. These researches would enable the progression of scientific knowledge in this area, as well as the routine of appropriate interventions, in order to reduce the prevalence of IEBs in this public.
16. Caqueo-Urízar A, Ferrer-García M, Toro J, Gutiérrez-Maldonado J, Peñaloza C, Cuadros-Sosa $Y$ et al. Associations between sociocultural pressures to be thin, body distress, and eating disorder symptomatology among Chilean adolescent girls. Body Image 2011;8:78-81.

17. Alves E, Vasconcelos Fde A, Calvo MC, Neves Jd. Prevalence of symptoms of anorexia nervosa and dissatisfaction with body image among female adolescents in Florianópolis, Santa Catarina State, Brazil. Cad Saude Publica 2008;24:503-12.

18. Bighetti F, Santos CB, Santos JE, Ribeiro RP. Translation and validation of the Eating Attitudes Test in female adolescents in Ribeirão Preto, SP, Brazil. J Bras Psiquiatr 2004;53:339-46.

19. Conti MA, Cordás TA, Latorre MR. A study of the validity and reliability of the Brazilian version of the Body Shape Questionnaire (BSQ) among adolescents. Rev Bras Saude Mater Infant 2009;9:331-8.

20. Associação Brasileira de Empresas de Pesquisa [homepage on the Internet]. Critério de Classificação Econômica Brasil [cited 2011 Feb 01]. Available from: http://www.abep.org/novo/FileGenerate.ashx?id=250

21. The Internacional Society for the Advancement of Kineanthropometry [homepage on the Internet]. Australia: National Library of Australia [cited 2010 May 10]. Available from: http://www.isakonline.com

22. Miranda VP, Conti MA, Bastos R, Ferreira ME. Body dissatisfaction in Brazilian adolescents from small municipalities of Minas Gerais. J Bras Psiquiatr 2011;60:190-7.

23. Kelly NR, Bulik CM, Mazzeo SE. An exploration of body dissatisfaction and perceptions of Black and White girls enrolled in an intervention for overweight children. Body Image 2011;8:379-84.

24. Mousa TY, Mashal RH, Al-Domi HA, Jibril MA. Body image dissatisfaction among adolescent schoolgirls in Jordan. Body Image 2010;7:46-50.

25. Fortes LS, Ferreira ME. Comparação da insatisfação corporal e do comportamento alimentar inadequado em atletas adolescentes de diferentes modalidades esportivas. Rev Bras Educ Fis Esporte 2011;25:707-16.

26. Finato S, Rech RR, Migon P, Gavineski IC, Toni V, Halpern R. Body image insatisfaction in students from the sixth grade of public schools in Caxias do Sul, Southern Brazil. Rev Paul Pediatr 2013;31:65-70.

27. Schubert A, Januário RS, Casonatto J, Sonoo CN. Body image, nutritional status, abdominal strength, and cardiorespiratory fitness in children and adolescents practicing sports. Rev Paul Pediatr 2013;31:71-6. 